\title{
Post-training reversible inactivation of the hippocampus enhances novel object recognition memory
}

\author{
Ana M.M. Oliveira, ${ }^{1}$ Joshua D. Hawk, Ted Abel, ${ }^{2}$ and Robbert Havekes ${ }^{2}$ \\ Department of Biology, University of Pennsylvania, Philadelphia, Pennsylvania 19104, USA
}

\begin{abstract}
Research on the role of the hippocampus in object recognition memory has produced conflicting results. Previous studies have used permanent hippocampal lesions to assess the requirement for the hippocampus in the object recognition task. However, permanent hippocampal lesions may impact performance through effects on processes besides memory consolidation including acquisition, retrieval, and performance. To overcome this limitation, we used an intrahippocampal injection of the GABA agonist muscimol to reversibly inactivate the hippocampus immediately after training mice in two versions of an object recognition task. We found that the inactivation of the dorsal hippocampus after training impairs object-place recognition memory but enhances novel object recognition (NOR) memory. However, inactivation of the dorsal hippocampus after repeated exposure to the training context did not affect object recognition memory. Our findings suggest that object recognition memory formation does not require the hippocampus and, moreover, that activity in the hippocampus can interfere with the consolidation of object recognition memory when object information encoding occurs in an unfamiliar environment.
\end{abstract}

The medial temporal lobe plays an important role in recognition memory formation, as damage to this brain structure in humans, monkeys, and rodents impairs performance in recognition memory tasks (for review, see Squire et al. 2007). Within the medial temporal lobe, studies have consistently demonstrated that the perirhinal cortex is involved in this form of memory (Brown and Aggleton 2001; Winters and Bussey 2005; Winters et al. 2007, 2008; Balderas et al. 2008). In contrast, the role of the hippocampus in object recognition memory remains a source of debate. Some studies have reported novel object recognition (NOR) impairments in animals with hippocampal lesions (Clark et al. 2000; Broadbent et al. 2004, 2010), yet others have reported no impairments (Winters et al. 2004; Good et al. 2007). Differences in hippocampal lesion size and behavioral procedures among the different studies have been implicated as the source of discrepancy in these findings (Ainge et al. 2006), but previous studies have not examined the consequences of environment familiarity on the hippocampus dependence of object recognition memory.

Previous studies addressing the role of the hippocampus in recognition memory relied on permanent, pre-training lesions (Clark et al. 2000; Broadbent et al. 2004; Winters et al. 2004; Good et al. 2007). Permanent lesions inactivate the hippocampus not only during the consolidation phase, but also during habituation, acquisition, and memory retrieval, potentially confounding interpretation of the results. Furthermore, permanent lesion studies require long surgery recovery times during which extrahippocampal changes may emerge to mask or compensate for the loss of hippocampal function. To overcome these problems, we reversibly inactivated the dorsal hippocampus after training mice in two versions of the object recognition task. We

\footnotetext{
1 Present address: Department of Neurobiology, University of Heidelberg, 69120 Heidelberg, Germany. ${ }^{2}$ Corresponding authors.

E-mail havekesr@sas.upenn.edu; (215) 573-1297.

E-mail abele@sas.upenn.edu; (215) 573-1297.

Article is online at http://www.learnmem.org/cgi/doi/10.1101/lm.1625310.
}

infused muscimol, a $\gamma$-aminobutyric acid (GABA) receptor type A agonist, into the dorsal hippocampus immediately after training in an object-place recognition task or immediately following training in a NOR task. Consistent with previous studies (Save et al. 1992; Galani et al. 1998; Mumby et al. 2002; Stupien et al. 2003; Aggleton and Brown 2005), we observed that hippocampal inactivation impairs object-place recognition memory. Interestingly, we observed that the degree of contextual familiarity can influence NOR memory formation. We found that when shorter periods of habituation to the experimental environment were used, hippocampal inactivation enhances long-term NOR memory. In contrast, after extended periods of contextual habituation, long-term recognition memory was unaltered by hippocampal inactivation. Together these results suggest that if familiarization with objects occurs at a stage in which the contextual environment is relatively novel, the hippocampus plays an inhibitory role on the consolidation of object recognition memory. Supporting this view, we observed that object recognition memory is unaffected by hippocampal inactivation when initial exploration of the objects occurred in a familiar environment.

\section{Results}

In this study, we inactivated the dorsal hippocampus using muscimol, a GABA receptor type A agonist that has been used previously to inhibit hippocampal activity (Moser and Moser 1998; Holt and Maren 1999; Maren and Hobin 2007). Muscimol was injected into the dorsal hippocampus through guide cannulae implanted in the mouse brain by stereotaxic surgery. Figure 1 shows a cresyl violet-stained coronal section illustrating a representative cannula placement in the dorsal hippocampus. Based on previously published results (Martin 1991; Lewis and Gould 2007), our infusions were likely to have diffused no more than 1 $\mathrm{mm}$ from the site of injection. Therefore, the major area of inactivation would center on the dorsal hippocampus.

The object-place recognition task exploits the natural exploratory activity of rodents toward spatial novelty to assess 


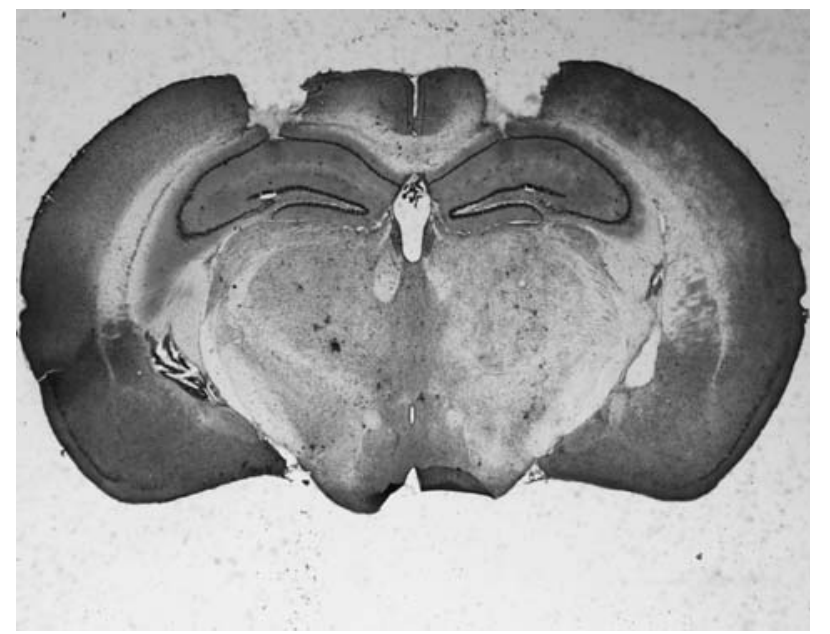

Figure 1. Cannulae placement in the dorsal hippocampus. A brain coronal section from a representative mouse showing cannulae placement in the dorsal hippocampus. Brain slices were stained with cresyl violet.

the detection of spatial relocation of a known object and is critically dependent on the hippocampus (Save et al. 1992; Stupien et al. 2003). After a 6-min habituation session in an empty arena, mice were exposed to the training context that now contained three distinct objects, for three consecutive 6-min training sessions (Fig. 2A). During the three training sessions, object exploration time gradually decreased (repeatedmeasured ANOVA, effect of session $\left.F_{(2,34)}=14.831, P<0.0001\right)$. During the first, second, and third training sessions, mice spent $24.1 \pm 2.2 \mathrm{sec}, 18.1 \pm 1.0 \mathrm{sec}$, and $15.9 \pm 1.2 \mathrm{sec}$, respectively, exploring the objects. No difference was found between the groups that would ultimately be treated with muscimol or saline (ANOVA, effect of group, $F_{(1,16)}=1.399, P>0.2$ ). Immediately after the last training session, mice received bilateral intrahippocampal injections of muscimol or saline. Twenty-four hours later, mice were re-exposed to the context with one of the three objects in a new location (Fig. 2B). A two-way ANOVA revealed an interaction effect between object location and treatment $\left(F_{(1,34)}=4.209, \quad P<0.05\right.$; Fig. $\left.2 \mathrm{~B}\right)$. The saline-injected mice spent more time exploring the displaced object and less time exploring the non-displaced objects during the retention test (paired-samples $t$-test, $P<0.05$; Fig. $2 \mathrm{~B}$ ). In contrast, mice that received intrahippocampal injections with the GABAergic agonist muscimol did not distinguish the displaced from the nondisplaced objects (paired-samples $t$-test, $P>0.8$; Fig. 2B). No differences in locomotor activity during training or testing were observed between the two groups (data not shown). These results confirm that the spatial object recognition task requires activity within the hippocampus and the ability of intrahippocampal muscimol injections to prevent memory formation in a hippocampus-dependent task.

The inhibition of hippocampal activity caused by posttraining muscimol injection is likely to be restricted to the consolidation phase of the memory task, because previous studies have shown that neuronal activity recovers in a few hours after drug treatment (Martin 1991; Allen et al. 2008; Herry et al. 2008). Moreover, the animals' ability to learn a task is recovered after muscimol administration (Wilensky et al. 2006; Allen et al. 2008; Herry et al. 2008). To confirm the temporary inhibitory effect of muscimol (Fig. 2C), we infused muscimol or saline into the dorsal hippocampus followed by training ( $24 \mathrm{~h}$ later) of the mice in the object-place recognition task (Fig. 2C). Both muscimol and saline groups gradually reduced exploration time during training (muscimol-treated group: $26.1 \pm 2.5 \mathrm{sec}, 21.5 \pm 2.5 \mathrm{sec}$, $16.1 \pm 2.0 \mathrm{sec}$; saline-treated group: $25.4 \pm 2.2 \mathrm{sec}, 22.9 \pm 2.3 \mathrm{sec}$, $15.3 \pm 1.7 \mathrm{sec}$; repeated-measures ANOVA effect of session: $\left.F_{(2,30)}=81.50, P<0.001\right)$. No difference was found between the groups that would ultimately be treated with muscimol or saline (ANOVA effect of group: $F_{(1,15)}=0.001, P>0.9$ and interaction group $\times$ session: $\left.F_{(2,30)}=1.176, \quad P>0.3\right)$. Additionally, both saline- and muscimol-injected mice spent more time exploring the displaced object and less time exploring the non-displaced objects during the retention test (effect of object location: $\left.F_{(1,30)}=14.14, P=0.01\right)$. No effect of drug treatment $\left(F_{(1,30)}=\right.$
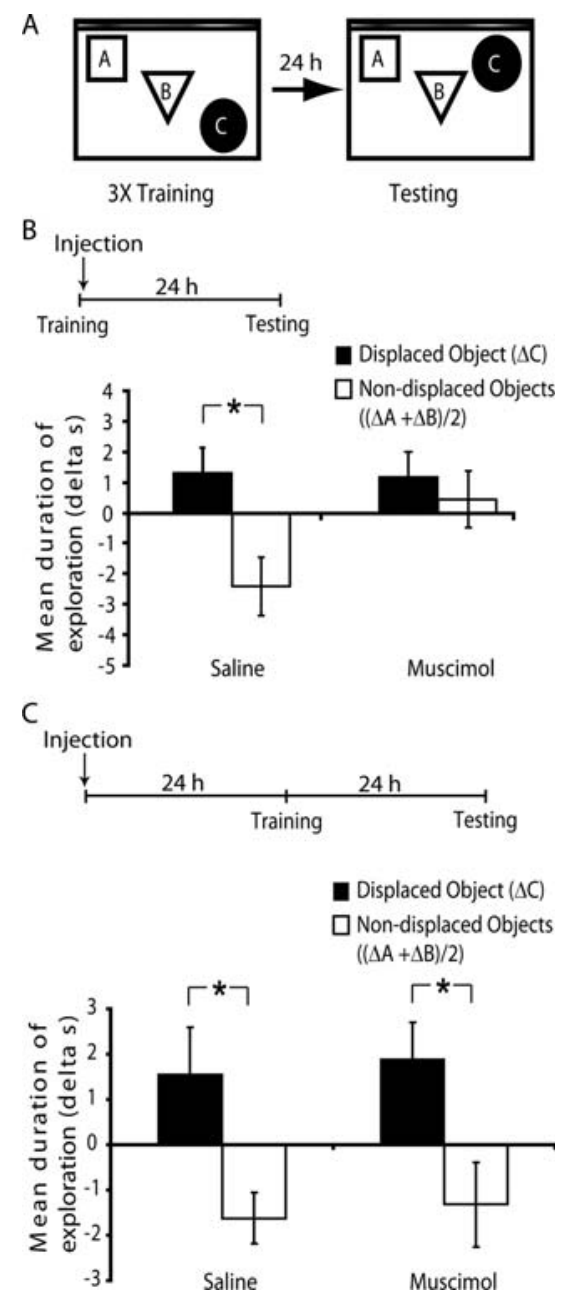

Figure 2. Post-training dorsal hippocampal inactivation impairs the formation of long-term object-place memory. $(A)$ Schematic representation of the open field and object locations during training and test sessions. $(B)$ Intrahippocampal injections occurred immediately after the training session. Mice that received intrahippocampal saline injections $(n=10)$ increased the time spent exploring the displaced object while decreasing the time spent exploring the non-displaced object during the test session. In contrast, mice that received intrahippocampal injections with the GABAergic agonist muscimol $(n=9)$ did not distinguish the displaced from the non-displaced object and slightly increased the time spent on both displaced and non-displaced objects during the test session. (C) Intrahippocampal injections occurred $24 \mathrm{~h}$ before the training session. Mice that received intrahippocampal saline $(n=8)$ or muscimol $(n=9)$ injections both increased the time spent exploring the displaced object while decreasing the time spent exploring the non-displaced object during the test session. ${ }^{*} P=0.05$. 
$0.262, P=0.6)$ or object location $\times$ treatment interaction effect was observed $\left(F_{(1,30)}=0.796, P=0.7\right)$, indicating that both groups successfully identified the spatial change in object location. This finding suggests that muscimol transiently inactivates the hippocampus and that hippocampal function recovers within $24 \mathrm{~h}$ after the muscimol injection. Therefore, the effects on memory observed when muscimol is infused immediately post-training (Figs. 2B, 3) cannot be explained by interference with memory retrieval, but rather by impairment of memory consolidation.

In contrast to the object-place recognition task, intrahippocampal infusion of muscimol immediately after training in the NOR task enhanced long-term recognition memory tested $24 \mathrm{~h}$ after training (Fig. 3). This enhanced memory was expressed as a significantly higher exploration time for the novel object during the test session in muscimol-treated mice as compared to salinetreated mice $\left(t_{(17)}=-3.40, P<0.05\right)$. Importantly, during the training (muscimol-treated group: $30.67 \pm 3.40 \mathrm{sec}$; saline-treated group: $37.45 \pm 6.52 \mathrm{sec}$ ) and test (muscimol-treated group: 20.1 $\pm 2.55 \mathrm{sec}$; saline-treated group: $20.4 \pm 2.8 \mathrm{sec}$ ) sessions, the muscimol-injected group showed a similar total time exploring both objects compared to the saline-treated group. This observation suggests that enhanced preference for the novel object in the muscimol-treated group is not due to increased exploratory activity.

Enhanced recognition memory following hippocampal inactivation has not been previously reported and suggests that the hippocampus may play an inhibitory role in object recognition memory formation. Object recognition encoding is thought to consist of at least two components: the learning of information about the identity of the object and the learning of information about the context in which these objects were found. The multiple memory systems that underlie these processes are most likely activated in parallel, and interference may arise as a result of this parallel activation of individual memory systems (Schroeder et al. 2002; Poldrack and Packard 2003; Stone et al. 2005). Therefore, we hypothesized that familiarization with the training context could reduce this interference and eliminate the memory-enhancing effect of intrahippocampal muscimol infusion. The extent of exploratory behavior is a means to measure familiarization with a novel context (Platel and Porsolt 1982; Eichenbaum 1996), and the reduction in exploratory

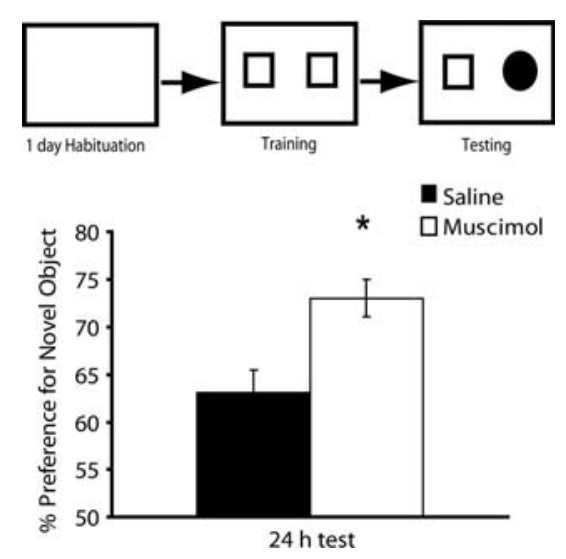

Figure 3. Post-training dorsal hippocampal inactivation enhances longterm object recognition memory. Mice were habituated to the empty arena $1 \mathrm{~d}$ prior to training. During the 24-h test, the muscimol-treated group $(n=10)$ exhibited significantly higher preference for the novel object compared to animals treated with saline $(n=10)$ when tested 24 h after training. ${ }^{*} P=0.05$.

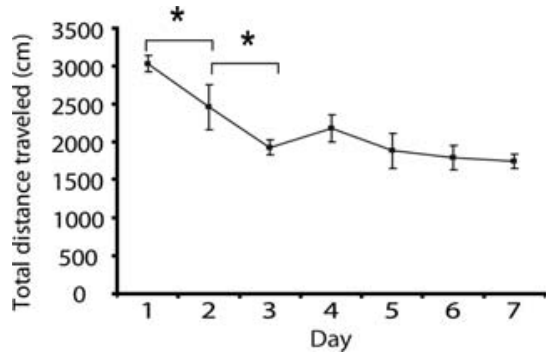

Figure 4. Time course of contextual habituation. Mice $(n=5)$ received daily exposures ( $5 \mathrm{~min}$ a day) to the empty experimental arena. The exploratory activity significantly decreased during the first $3 \mathrm{~d}$. From day 3 , mice showed constant exploratory behavior. ${ }^{*} P=0.05$.

behavior with repeated context exposure, known as habituation, is dependent on an intact hippocampus (Manahan-Vaughan and Braunewell 1999; Vianna et al. 2000; Kemp and ManahanVaughan 2004; Ramirez-Amaya et al. 2005; Etkin et al. 2006). To determine the time course of contextual habituation, we habituated a new group of mice to the experimental apparatus for 5 min per day for seven consecutive days and scored the total distance traveled in the arena as a measure of exploration (Fig. 4). During this habituation period, mice gradually decreased the total distance traveled across days of exposure to the experimental environment, reflecting increased familiarization (repeatedmeasures ANOVA effect of day: $\left.F_{(6,24)}=13.89, P<0.0001\right)$. The total distance traveled reduced significantly during the first $3 \mathrm{~d}$ $(P<0.05$, for both day 1 vs. day 2 and day 2 vs. day 3$)$, and the total distance traveled reached a plateau after the third day $(P>$ 0.05 , the total distance traveled during day 3 is not different from days 4-7), suggesting that after three consecutive days of habituation the animals reached their maximum level of familiarization with the environment.

We then performed a second NOR experiment in which a new group of mice received extended habituation to the training context ( $5 \mathrm{~d}$ of habituation were chosen since at this time point, based on the previous experiment, mice are familiar with the context). Immediately after training, mice were infused with muscimol or saline into the hippocampus. Both saline- and muscimol-injected mice show equivalent preferential exploration of the novel object during the test session, indicating that hippocampal inactivation during the consolidation phase did not have an effect on novel object preference after extended habituation to the training context (Fig. 5). The total exploration times were not different during training (muscimol-treated group: $23.33 \pm 4.86$ sec; saline-treated group: $22.52 \pm 2.92 \mathrm{sec}$ ) and testing (muscimoltreated group: $13.61 \pm 2.04 \mathrm{sec}$; saline-treated group: $12.69 \pm 2.35$ $\mathrm{sec})$ sessions between the two groups, indicating that muscimol treatment did not alter the total level of exploration.

In summary, we have found that intrahippocampal infusion of muscimol impairs memory consolidation in the object-place recognition task and enhances memory consolidation in the NOR task when performed in a less familiar environment. In contrast, inactivation of the hippocampus after extended context habituation does not impact long-term object recognition memory.

\section{Discussion}

In this study we have used a reversible inactivation method to assess the role of the hippocampus in object-place and NOR memory. We found that the inactivation of the hippocampus immediately after training impairs object-place recognition memory, but enhances object recognition memory. However, 


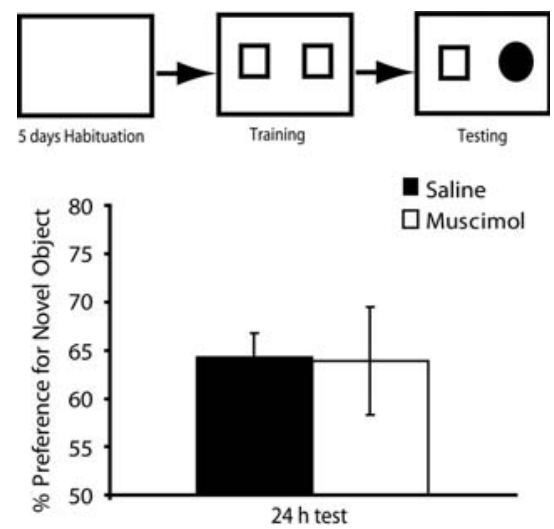

Figure 5. Hippocampal inactivation has no effect on novel object recognition memory when training occurs in a familiar environment. Mice were habituated to the empty arena for $5 \mathrm{~d}$ prior to training. During the testing session, the muscimol-treated group $(n=6)$ exhibited a similar preference for the novel object compared with animals treated with saline $(n=10)$ when tested $24 \mathrm{~h}$ after training.

inactivation of the hippocampus after repeated exposure to the training context does not affect object recognition memory.

Our study supports the view that the consolidation of object recognition memory is independent of hippocampal function (Winters et al. 2004, 2008; Forwood et al. 2005; O'Brien et al. 2006; Langston and Wood 2009). In line with our findings, a recent study found that the protein synthesis inhibitor anisomycin did not impair object recognition memory consolidation when infused into the hippocampus immediately after training in an object recognition task (Balderas et al. 2008). In fact, the inconsistent and contradictory results concerning the role of the hippocampus in object recognition memory led to the hypothesis that the hippocampus is only important for NOR when spatial or contextual cues are relevant during the encoding of the object information. Indeed, studies with rats showed that when NOR is performed in a complex spatial environment, hippocampal lesions impair memory formation, whereas if contextual and spatial cues are minimized, hippocampal inactivation had no effect on object recognition memory (Winters et al. 2004; Forwood et al. 2005; Langston and Wood 2009). These findings suggest that if the objects are presented in a rich environment, they may be encoded as part of the context, thus involving the hippocampus. In contrast, if the objects are presented in an impoverished environment, they are encoded independent of the environment, in a manner that does not involve the hippocampus.

Our results further suggest that competitive interference between multiple memory systems may be present during the post-training period (consolidation phase) in the NOR task, as has been observed previously for other memory tasks (for review, see Schroeder et al. 2002; Poldrack and Packard 2003; Stone et al. 2005; Winters et al. 2007). In contrast to the view suggesting a central role for the hippocampal system in memory formation generally, several studies have demonstrated that inactivation of the hippocampal structure does not induce a generalized amnesia, but rather causes impairments in specific types of memory. These observations led to the multiple memory systems hypothesis (Poldrack and Packard 2003). The multiple memory systems hypothesis is further supported by demonstrations of dissociations following inactivation of distinct brain regions in which inactivation of one brain region impairs task $\mathrm{A}$ but spares task B (Kesner et al. 1993; McDonald and White 1993, 1994; Packard 2009). Multiple memory systems are most likely activated in parallel, allowing interference to arise.
Competitive interference between memory systems was demonstrated by studies performing hippocampal lesions that resulted in the facilitation of acquisition of a memory task likely through elimination of interference (Eichenbaum et al. 1988; Packard et al. 1989; Poldrack and Packard 2003; Saksida et al. 2007).

The hippocampus is required for contextual information processing, and multiple studies have shown that the perirhinal cortex is involved in the consolidation of object information (Brown and Aggleton 2001; Winters and Bussey 2005; Winters et al. 2007). We have confirmed the requirement for the hippocampus in a spatial memory task and are the first to show that the object recognition memory is enhanced when the hippocampus is inactivated during the consolidation phase, implying that a normally functioning hippocampus may interfere with the process of object familiarization. One possible interpretation of this observation is that competitive interference is present during the post-training period, such that the blockade of consolidation of contextual information allows consolidation of the object information to occur to a greater extent. Previous studies have demonstrated similar competitive interference during memory consolidation (Schroeder et al. 2002; Stone et al. 2005). Analogous with those findings, another possible interpretation of our results would be that mice either encode object information as part of the context (this situation would occur when objects are presented in an unfamiliar environment) or use a nonspatial strategy in which object information is encoded independent of contextual landmarks. Interference between these two strategies may arise, such that elimination of the spatial strategy by hippocampal inactivation allows the nonspatial strategy to occur more efficiently. Thus, by eliminating this competitive interference process, hippocampal inactivation would lead to the observed enhanced NOR memory. In contrast, when the objects are presented in a familiar environment, a contextual object information-encoding strategy would not occur because the context has previously been encoded in the absence of objects, leading to a hippocampusindependent encoding of object identity.

Recently, Stefanko et al. (2009) demonstrated that mice receiving training in an object recognition task with no previous contextual habituation exhibit impaired object recognition memory compared to mice that were extensively habituated to the context. This difference could not be attributed to the duration of the exploration of the objects as both groups spent the same percentage of time in contact with the objects. This study agrees with our findings because it suggests that processing of contextual information of a newly encountered environment may interfere with the consolidation of the information that characterizes the objects, leading, in this case, to a poorer memory of the familiar object (Stefanko et al. 2009).

The use of post-training inhibition of the hippocampus allowed us to determine the role of hippocampal activity in consolidation of object recognition memory by avoiding potential nonmnemonic confounds that can arise from pre-training permanent lesions such as motor, sensory, attentional, and motivational influences on task performance. This study highlights the competition of multiple memory systems in different brain areas during memory formation. We have not identified the brain region(s) influenced by hippocampal interference; however, one promising candidate region is the perirhinal cortex, as it is anatomically connected with the hippocampus and is involved in the acquisition of object information (Winters et al. 2008).

\section{Materials and Methods}

Mice

Male C57BL/6J mice were used in this study. Mice were 8-14 wk old and had free access to food and water in their home cages. 
Lights were maintained on a 12-h light/dark cycle, with all behavioral testing performed during the light portion of the cycle. Mice were singly housed from surgery day onward and allowed to recover for $1 \mathrm{wk}$. A different set of mice was used in each behavioral experiment. All experiments were carried out in accordance with National Institutes of Health guidelines and were approved by the Institutional Animal Care and Use Committee of the University of Pennsylvania.

\section{Cannula placement}

Bilateral 22-gauge guide cannulae were used to guide an injection cannula into the dorsal hippocampus. The guide cannulae were held in place using dental glue (ESPE Ketac-Fil Plus Aplicap Glass Ionomer, $3 \mathrm{M}$ ). The target injection site coordinates were as follows: anteroposterior, $-1.7 \mathrm{~mm}$; mediolateral, $\pm 1.5 \mathrm{~mm}$; dorsoventral, $-1.5 \mathrm{~mm}$ (Vecsey et al. 2007). The behavioral experiments started 1 wk after surgery.

\section{Behavior}

\section{Object-place recognition task}

The experimental apparatus consisted of a gray rectangular open field $(60 \mathrm{~cm} \times 50 \mathrm{~cm} \times 26 \mathrm{~cm})$ with a visual cue placed on the arena wall. Prior to training, mice were handled for $1 \mathrm{~min}$ a day for $3 \mathrm{~d}$. During the training day, mice received four 6 min training sessions. Between sessions, mice were put back in their home cage for $3 \mathrm{~min}$. During the first session, mice were habituated to the gray rectangular open field in the absence of objects, but with an internal cue on one of the four walls. During the next three sessions, mice were placed in the same box but now with three distinct objects. The objects consisted of a glass bottle, a metal tower, and a plastic cylinder. Mice were allowed to freely explore the environment and the objects for $6 \mathrm{~min}$. After $24 \mathrm{~h}$, mice were placed back in the rectangular environment for the testing phase. The three objects were again present, but one of the three objects was now displaced to a novel spatial location. Mice were again allowed to freely explore the environment and the objects for $6 \mathrm{~min}$. Time spent exploring the displaced and non-displaced objects was measured. Exploration was analyzed during both the training and testing phases. The identity of the objects as well as the spatial location in which the objects were located was balanced between subjects.

The response to spatial change was assessed by comparing the mean time the mice spent exploring the objects (when mice were facing and sniffing the objects within very close proximity and/or touching them) belonging to each category (displaced and non-displaced) in the test session minus the mean time spent in contact with the same object category in the last training session. A positive value indicates recognition of the spatial change.

\section{Novel object recognition (NOR) task}

The experimental apparatus consisted of a white rectangular open field $(60 \mathrm{~cm} \times 50 \mathrm{~cm} \times 26 \mathrm{~cm})$. Prior to training, mice were handled for $1 \mathrm{~min}$ a day for $3 \mathrm{~d}$. Habituation took place by exposing the animal to the experimental apparatus for $5 \mathrm{~min}$ in the absence of objects one time, on the day before training, or five times during five consecutive days before training. During the training phase mice were placed in the experimental apparatus in the presence of two identical objects and allowed to explore for $15 \mathrm{~min}$. After a retention interval of $24 \mathrm{~h}$, mice were placed again in the apparatus, where this time one of the objects was replaced by a novel one. Mice were allowed to explore for 15 min. Preference for the novel object was expressed as the percent time spent exploring the novel object relative to the total time spent exploring both objects. The objects were a glass conical flask and a plastic rectangular box, both with approximately the same height. The identity of the objects-which one was novel or familiar-as well as the spatial location (whether the novel object was placed on the left or right side during the test session) of each object was balanced between groups. A preference for either object was not observed in this study.

Each group's ability to recognize the novel object was determined by dividing the mean time exploring the novel object by the mean of the total time exploring the novel and familiar objects during the test session. This value was multiplied by 100 to obtain a percentage preference for the novel object ( $T_{\text {novel }} /$ $\left.\left[T_{\text {novel }}+T_{\text {familiar }}\right] \times 100\right)$.

In both tasks, objects were rinsed with ethanol between trials and before the first trial. All testing and training sessions were videotaped and analyzed by an experimenter blind to the treatment of the animals. It was considered exploration of the objects when mice were facing and sniffing the objects within very close proximity and/or touching.

Exploratory activity in the experimental arena was measured with the use of TopScan (Clever Systems Inc.).

\section{Injections}

Immediately after training or $24 \mathrm{~h}$ before training, mice received bilateral intrahippocampal injections of muscimol. Injections were done using a $5-\mu \mathrm{L}$ Hamilton syringe operated by a Harvard Apparatus Pump II Dual Syringe micropump. Injection cannulae were left in place an additional $60 \mathrm{sec}$ to allow the fluid to diffuse. Each side was injected individually, one immediately after the other; $0.5 \mu \mathrm{L}$ of $1 \mu \mathrm{g} / \mu \mathrm{L}$ muscimol (Sigma) dissolved in $0.9 \%$ saline was injected per side at a $0.5-\mu \mathrm{L} / \mathrm{min}$ rate (Lewis and Gould 2007).

\section{Histology}

After each behavioral experiment, mice were sacrificed by cervical dislocation, and the brains were immediately removed and stored in $4 \%$ PFA until sectioning. Coronal sections $(30 \mu \mathrm{m})$ were cut on a cryostat and mounted on slides. The slides were stained with cresyl violet, and the injection sites were verified under a light microscope by an experimenter blind to the treatment.

\section{Statistical analyses}

In case of the object-place recognition task, a repeated-measures ANOVA was used to analyze the exploration times during training. A two-way ANOVA and paired samples $t$-tests were used to analyze the time spent exploring the displaced and non-displaced objects. Student's $t$-tests were used to analyze the preference for the novel object. The distance traveled during the repeated contextual exposures was analyzed using a repeated-measures ANOVA followed by the Student-Newman-Keuls multiple comparisons post-hoc test.

\section{Acknowledgments}

This work was supported by grants from Human Frontiers (to T.A.), National Institutes of Health (to T.A.), Netherlands Organization for Scientific Research (to R.H.), and Foundation for Science and Technology, Portugal (to A.M.M.O.).

\section{References}

Aggleton JP, Brown MW. 2005. Contrasting hippocampal and perirhinal cortex function using immediate early gene imaging. QJ Exp Psychol B 58: $218-233$

Ainge JA, Heron-Maxwell C, Theofilas P, Wright P, de Hoz L, Wood ER. 2006. The role of the hippocampus in object recognition in rats: Examination of the influence of task parameters and lesion size. Behav Brain Res 167: 183-195.

Allen TA, Narayanan NS, Kholodar-Smith DB, Zhao Y, Laubach M, Brown TH. 2008. Imaging the spread of reversible brain inactivations using fluorescent muscimol. J Neurosci Methods 171: 30-38.

Balderas I, Rodriguez-Ortiz CJ, Salgado-Tonda P, Chavez-Hurtado J, McGaugh JL, Bermudez-Rattoni F. 2008. The consolidation of object and context recognition memory involve different regions of the temporal lobe. Learn Mem 15: 618-624.

Broadbent NJ, Squire LR, Clark RE. 2004. Spatial memory, recognition memory, and the hippocampus. Proc Natl Acad Sci 101: 14515-14520. 
Broadbent NJ, Gaskins S, Squire LR, Clark RE. 2010. Object recognition memory and the rodent hippocampus. Learn Mem 17: 5-11.

Brown MW, Aggleton JP. 2001. Recognition memory: What are the roles of the perirhinal cortex and hippocampus? Nat Rev 2: 51-61.

Clark RE, Zola SM, Squire LR. 2000. Impaired recognition memory in rats after damage to the hippocampus. J Neurosci 20: 8853-8860.

Eichenbaum H. 1996. Is the rodent hippocampus just for "place"? Curr Opin Neurobiol 6: 187-195.

Eichenbaum H, Fagan A, Mathews P, Cohen NJ. 1988. Hippocampal system dysfunction and odor discrimination learning in rats: Impairment or facilitation depending on representational demands. Behav Neurosci 102: $331-339$

Etkin A, Alarcon JM, Weisberg SP, Touzani K, Huang YY, Nordheim A, Kandel ER. 2006. A role in learning for SRF: Deletion in the adult forebrain disrupts LTD and the formation of an immediate memory of a novel context. Neuron 50: 127-143.

Forwood SE, Winters BD, Bussey TJ. 2005. Hippocampal lesions that abolish spatial maze performance spare object recognition memory at delays of up to $48 \mathrm{~h}$. Hippocampus 15: 347-355.

Galani R, Weiss I, Cassel JC, Kelche C. 1998. Spatial memory, habituation, and reactions to spatial and nonspatial changes in rats with selective lesions of the hippocampus, the entorhinal cortex or the subiculum. Behav Brain Res 96: 1-12.

Good MA, Barnes P, Staal V, McGregor A, Honey RC. 2007. Context- but not familiarity-dependent forms of object recognition are impaired following excitotoxic hippocampal lesions in rats. Behav Neurosci 121: $218-223$.

Herry C, Ciocchi S, Senn V, Demmou L, Muller C, Luthi A. 2008. Switching on and off fear by distinct neuronal circuits. Nature 454: 600-606.

Holt W, Maren S. 1999. Muscimol inactivation of the dorsal hippocampus impairs contextual retrieval of fear memory. J Neurosci 19: 9054-9062.

Kemp A, Manahan-Vaughan D. 2004. Hippocampal long-term depression and long-term potentiation encode different aspects of novelty acquisition. Proc Natl Acad Sci 101: 8192-8197.

Kesner RP, Bolland BL, Dakis M. 1993. Memory for spatial locations, motor responses, and objects: Triple dissociation among the hippocampus, caudate nucleus, and extrastriate visual cortex. Exp Brain Res 93: $462-470$.

Langston RF, Wood ER. 2009. Associative recognition and the hippocampus: Differential effects of hippocampal lesions on object-place, object-context and object-place-context memory. Hippocampus doi: 10.1002/hipo.20714.

Lewis MC, Gould TJ. 2007. Reversible inactivation of the entorhinal cortex disrupts the establishment and expression of latent inhibition of cued fear conditioning in C57BL/6 mice. Hippocampus 17: 462-470.

Manahan-Vaughan D, Braunewell KH. 1999. Novelty acquisition is associated with induction of hippocampal long-term depression. Proc Natl Acad Sci 96: 8739-8744.

Maren S, Hobin JA. 2007. Hippocampal regulation of context-dependent neuronal activity in the lateral amygdala. Learn Mem 14: 318-324

Martin JH. 1991. Autoradiographic estimation of the extent of reversible inactivation produced by microinjection of lidocaine and muscimol in the rat. Neurosci Lett 127: 160-164.

McDonald RJ, White NM. 1993. A triple dissociation of memory systems: Hippocampus, amygdala, and dorsal striatum. Behav Neurosci 107: $3-22$.

McDonald RJ, White NM. 1994. Parallel information processing in the water maze: Evidence for independent memory systems involving dorsal striatum and hippocampus. Behav Neural Biol 61: 260-270.

Moser MB, Moser EI. 1998. Distributed encoding and retrieval of spatial memory in the hippocampus. J Neurosci 18: 7535-7542.

Mumby DG, Gaskin S, Glenn MJ, Schramek TE, Lehmann H. 2002. Hippocampal damage and exploratory preferences in rats: Memory for objects, places, and contexts. Learn Mem 9: 49-57.

O'Brien N, Lehmann H, Lecluse V, Mumby DG. 2006. Enhanced context-dependency of object recognition in rats with hippocampal lesions. Behav Brain Res 170: 156-162.
Packard MG. 2009. Anxiety, cognition, and habit: A multiple memory systems perspective. Brain Res 1293: 121-128.

Packard MG, Hirsh R, White NM. 1989. Differential effects of fornix and caudate nucleus lesions on two radial maze tasks: Evidence for multiple memory systems. J Neurosci 9: 1465-1472.

Platel A, Porsolt RD. 1982. Habituation of exploratory activity in mice: A screening test for memory enhancing drugs. Psychopharmacology 78: 346-352.

Poldrack RA, Packard MG. 2003. Competition among multiple memory systems: Converging evidence from animal and human brain studies. Neuropsychologia 41: 245-251.

Ramirez-Amaya V, Vazdarjanova A, Mikhael D, Rosi S, Worley PF, Barnes CA. 2005. Spatial exploration-induced Arc mRNA and protein expression: Evidence for selective, network-specific reactivation. J Neurosci 25: 1761-1768.

Saksida LM, Bussey TJ, Buckmaster CA, Murray EA. 2007. Impairment and facilitation of transverse patterning after lesions of the perirhinal cortex and hippocampus, respectively. Cereb Cortex 17: 108-115.

Save E, Poucet B, Foreman N, Buhot MC. 1992. Object exploration and reactions to spatial and nonspatial changes in hooded rats following damage to parietal cortex or hippocampal formation. Behav Neurosci 106: $447-456$.

Schroeder JP, Wingard JC, Packard MG. 2002. Post-training reversible inactivation of hippocampus reveals interference between memory systems. Hippocampus 12: 280-284.

Squire LR, Wixted JT, Clark RE. 2007. Recognition memory and the medial temporal lobe: A new perspective. Nature Rev 8: 872-883.

Stefanko DP, Barrett RM, Ly AR, Reolon GK, Wood MA. 2009. Modulation of long-term memory for object recognition via HDAC inhibition. Proc Natl Acad Sci 106: 9447-9452.

Stone ME, Grimes BS, Katz DB. 2005. Hippocampal inactivation enhances taste learning. Learn Mem 12: 579-586.

Stupien G, Florian C, Roullet P. 2003. Involvement of the hippocampal CA3-region in acquisition and in memory consolidation of spatial but not in object information in mice. Neurobiol Learn Mem 80: $32-41$.

Vecsey CG, Hawk JD, Lattal KM, Stein JM, Fabian SA, Attner MA, Cabrera SM, McDonough CB, Brindle PK, Abel Tet al. 2007. Histone deacetylase inhibitors enhance memory, synaptic plasticity via CREB:CBP-dependent transcriptional activation. J Neurosci 27: $6128-6140$.

Vianna MR, Alonso M, Viola H, Quevedo J, de Paris F, Furman M, de Stein ML, Medina JH, Izquierdo I. 2000. Role of hippocampal signaling pathways in long-term memory formation of a nonassociative learning task in the rat. Learn Mem 7: 333-340.

Wilensky AE, Schafe GE, Kristensen MP, LeDoux JE. 2006. Rethinking the fear circuit: The central nucleus of the amygdala is required for the acquisition, consolidation, and expression of Pavlovian fear conditioning. J Neurosci 26: 12387-12396.

Winters BD, Bussey TJ. 2005. Transient inactivation of perirhinal cortex disrupts encoding, retrieval, and consolidation of object recognition memory. J Neurosci 25: 52-61.

Winters BD, Forwood SE, Cowell RA, Saksida LM, Bussey TJ. 2004. Double dissociation between the effects of peri-postrhinal cortex and hippocampal lesions on tests of object recognition and spatial memory: Heterogeneity of function within the temporal lobe. J Neurosci 24: 5901-5908.

Winters BD, Bartko SJ, Saksida LM, Bussey TJ. 2007. Scopolamine infused into perirhinal cortex improves object recognition memory by blocking the acquisition of interfering object information. Learn Mem 14: $590-596$.

Winters BD, Saksida LM, Bussey TJ. 2008. Object recognition memory: Neurobiological mechanisms of encoding, consolidation and retrieval. Neurosci Biobehav Rev 32: 1055-1070.

Received September 13, 2009; accepted in revised form December 16, 2009. 


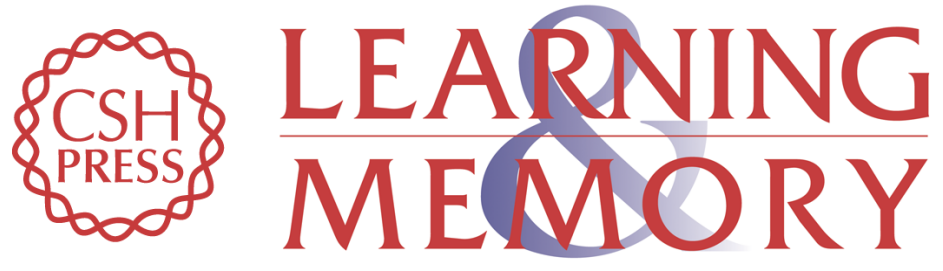

\section{Post-training reversible inactivation of the hippocampus enhances novel object recognition memory}

Ana M.M. Oliveira, Joshua D. Hawk, Ted Abel, et al.

Learn. Mem. 2010, 17:

Access the most recent version at doi:10.1101//m.1625310

References This article cites 46 articles, 20 of which can be accessed free at:

http://learnmem.cshlp.org/content/17/3/155.full.html\#ref-list-1

License

Email Alerting Receive free email alerts when new articles cite this article - sign up in the box at the Service top right corner of the article or click here. 